\title{
ZINC MODULATION OF MACROPHAGES INTERLEUKIN 1 GENE EXPRESSION AND SECRETION
}

\author{
A. E. Aguilar, R. Pastelin, S. Pérez, and M. D. Lastra \\ Laboratorio de Investigación en Inmunología \\ Departamento de Biología \\ Facultad de Química, UNAM \\ Circuito Escolar, Ciudad Universitaria, México \\ DF, CP 04510
}

Trace elements particularly $\mathrm{Zn}$, have a great influence in the development and maintenance of the immune system. The role of $\mathrm{Zn}$ in the improvement of impaired immunity is well documented. The macrophage appears to be more susceptible to $\mathrm{Zn}$ intervention. IL-1 secretion is characteristic of macrophage activation, thus its modulation by $\mathrm{Zn}$ could result in the immune response elevation. We addressed this question by designing a model of BALB/c mice supplemented with $\mathrm{Zn}(500 \mathrm{mg} / \mathrm{L})$ during gestation, lactation and postweaning. We investigated the possibility of zinc modulation of IL-1.

We report that $\mathrm{Zn}$ can enhance the IL-1 gene expression on macrophages activated by LPS. Kinetic studies of IL-1 gene expression evaluated by RT-PCR, showed a maximum level of induction $4 \mathrm{~h}$ after treatment with zinc, followed by a decrease to basal levels within $10 \mathrm{~h}$.

IL-1 secretion evaluated by an ELISA assay, showed an increment in LPS stimulated peritoneal macrophages supernatant after the lactation period ( 6 weeks treatment) with a drop after the postweaning period ( 9 weeks treatment). IL-1 serum concentrations showed a significant increment after 6 weeks of zinc supplementation with no variation after 9 weeks.

Results suggest an important role of zinc in macrophages stimulation, which carefully monitored could result in modulation of the monokine secretion and even modification of its seric concentrations. 